\title{
Shaping applied epidemiology workforce training to strengthen emergency response: a global survey of applied epidemiologists, 2019-2020
}

\author{
Amy Elizabeth Parry ${ }^{1^{*}} \mathbb{0}$, Martyn D. Kirk $\mathbb{B}^{1}$, David N. Durrheim² ${ }^{\mathbb{D}}$, Babatunde Olowokure ${ }^{3}$, \\ Samantha M. Colquhoun ${ }^{1}$ (1) and Tambri Housen ${ }^{1,2}$ (1)
}

\begin{abstract}
Background: Rapid and effective emergency response to address health security relies on a competent and suitably trained local and international workforce. The COVID-19 pandemic has highlighted that the health security workforce needs to be well equipped to tackle current and future challenges. In this study, we explored whether training in applied epidemiology was meeting the current needs of the applied epidemiology workforce.

Method: We conducted a cross-sectional online survey that was available in English and French. We used purposive and snowballing sampling techniques to identify potential survey respondents. An online social media advertisement campaign was used to disseminate a REDCap survey link between October 2019 and February 2020 through field epidemiology networks. Survey questions included demographic details of participants, along with their technical background, level of formal education, topics studied during epidemiology training, and years of experience as an epidemiologist. We used Pearson Chi-squared $\left(\mathrm{Chi}^{2}\right)$ to test the difference between categorical variables, and content analysis to evaluate responses to open-ended questions.

Results: In total, 282 people responded to the survey. Participants had a range of formal public health and epidemiology training backgrounds. Respondents applied epidemiology experience spanned almost 30 years, across 64 countries. Overall, 74\% $(n=210)$ were alumni of Field Epidemiology Training Programs (FETP). Basic outbreak and surveillance training was well reported by respondents, however training in specialised techniques related to emergency response, communication, and leadership was less common. FETP graduates reported higher levels of formal training in all survey topics.
\end{abstract}

Conclusion: It is critical for the health security workforce to be well-trained and equipped with skills needed to ensure a rapid and effective response to acute public health events. Leadership, communication, interpersonal skills, and specialist training in emergency response are lacking in current training models. Our study has demonstrated that applied epidemiology workforce training must evolve to remain relevant to current and future public health challenges.

\footnotetext{
*Correspondence: amy.parry@anu.edu.au

${ }^{1}$ National Centre for Epidemiology and Population Health, Research

School of Population Health, The Australian National University, Building

62 Mills Road, Acton, Australian Capital Territory, Australia

Full list of author information is available at the end of the article
}

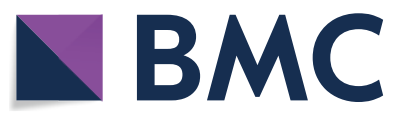

(c) The Author(s) 2021. Open Access This article is licensed under a Creative Commons Attribution 4.0 International License, which permits use, sharing, adaptation, distribution and reproduction in any medium or format, as long as you give appropriate credit to the original author(s) and the source, provide a link to the Creative Commons licence, and indicate if changes were made. The images or other third party material in this article are included in the article's Creative Commons licence, unless indicated otherwise in a credit line to the material. If material is not included in the article's Creative Commons licence and your intended use is not permitted by statutory regulation or exceeds the permitted use, you will need to obtain permission directly from the copyright holder. To view a copy of this licence, visit http://creativecommons.org/licenses/by/4.0/. The Creative Commons Public Domain Dedication waiver (http://creativeco mmons.org/publicdomain/zero/1.0/) applies to the data made available in this article, unless otherwise stated in a credit line to the data. 
Keywords: Epidemiology, Public health practice, Health workforce, Emergency, Education, Emergencies

\section{Background}

Rapid and effective emergency response to address health security challenges relies heavily on a competent and suitably trained local and international workforce $[1,2]$. The COVID-19 pandemic highlighted the importance of having a well-equipped health security workforce. Future epidemics of emerging infectious disease and other acute public health emergencies will continue to occur. To respond to these events, it is essential that training programs are providing graduates with the skills they need [3].

Well-trained field and applied epidemiologists are a crucial component of the health security workforce to prepare and effectively respond to health emergencies $[1,4]$. Applied epidemiologists work in government and non-government organisations to detect, investigate, manage, and control infectious diseases $[1,4,5]$, and have been described as "activists" who rapidly transform findings into policy and action [6].

Responsibility for applied epidemiology workforce development varies depending on the country $[7,8]$. The Field Epidemiology Training Program (FETP) model [7] is a learn-by-doing training approach $[4,8,9]$, where trainees are imbedded within their national health system. FETPs aim to improve public health systems through strengthening disease surveillance for evidence-based decision-making, and enhancing capacity for outbreak prevention, detection and response [8]. This training can vary in duration from 3 months for 'frontline' programs through to the 2 years for 'advanced' programs and are largely supported by Government health departments [10]. Academic institutions provide Master of Public Health or Epidemiology Programs, offering training in basic or advanced epidemiology, and biostatistics, with some offering specialist training in disaster management and/or humanitarian crisis management [11, 12].

The Ebola outbreak in West Africa, and more recently the COVID-19 pandemic, demonstrated the fragility of national and international public health response models [2]. These public health events have exposed the broader health system and health security implications of underinvesting in public health systems and training field epidemiologists [2]. There is an urgent need to review the investment in health security workforce development, to ensure countries have an appropriately skilled and confident workforce to rapidly manage and contain public health emergencies.

In 2019, we interviewed public health experts about the needs and challenges of the epidemiology emergency response workforce. Experts outlined the need for collective competence and discussed the lack of training standardisation, the need for skills in leadership, communication, and also specialist training in emergency response [13]. To understand if current models of applied epidemiology training were meeting the needs of the emergency response workforce and to identify training needs, we conducted an online survey administered to applied epidemiologists. We analysed survey data to understand the knowledge and skills obtained during education and training in applied epidemiology.

\section{Methods}

As part of a larger study looking at the effectiveness of the epidemiology workforce during emergency response [14], (Fig. 1) we conducted an online cross-sectional survey to identify training needs from the perspective of applied epidemiologists. For the purposes of this study, the 'applied epidemiology workforce' was defined as any

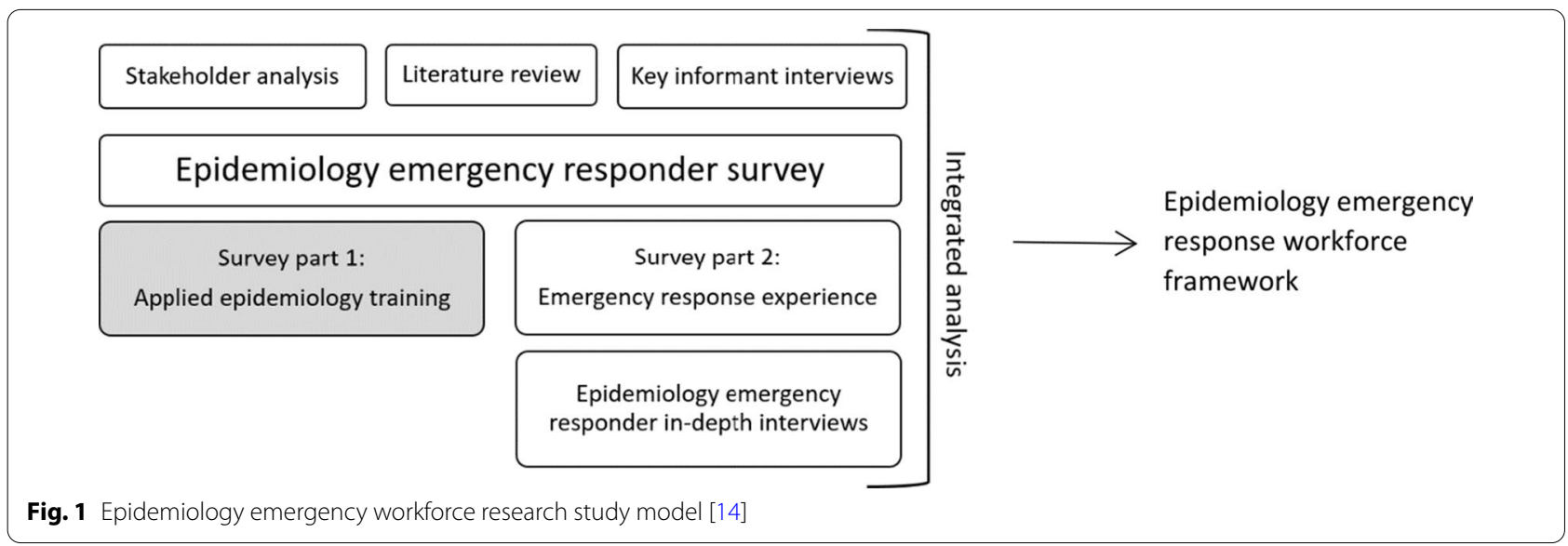


person working in an applied or field epidemiology role or acute public health responder role.

\section{Study population}

The target population for this survey was the global applied epidemiology workforce. We specifically targeted FETP alumni, however the survey was open to all people who had studied epidemiology and used this training in a practical setting.

\section{Sampling}

As there was no defined and reliable sampling frame, a combination of purposive and snowballing sampling techniques was used to identify the target population [15, 16].

Although the size of our study population for this survey was unknown due to our multiple recruitment methods, the primary means for survey distribution was the TEPHIConnect field epidemiology database, with 1700 registered active members as of September 2019. Using this as an indicative sampling frame, and the response rate from a previous unpublished survey by TEPHIConnect of $9.8 \%$, we assessed that the final sample size of 282 in this study would to lead to estimates of a single proportion with a $95 \%$ confidence interval, with precision of $\pm 6 \%$, after employing the finite population correction.

\section{Recruitment}

We recruited survey respondents through multiple sources. A YouTube video described the purpose of the study in English; this video included the option of subtitles in English or French. This video formed the basis of a social media recruitment campaign through Twitter, LinkedIn, and our dedicated study Facebook page. We disseminated participation reminders eight times through these social media channels over a 3-month period. We partnered with the global field epidemiology training alumni network, TEPHIConnect, who ran a social media campaign mirroring our campaign. The campaign stated that any person working in an applied epidemiology role could complete the survey. Individuals self-selected based on this criterion.

Postcards advertising the survey were distributed at the 10th TEPHINET Global Scientific Conference, the Australian Communicable Diseases Control Conference 2019, and the European Scientific Conference on Applied Infectious Disease Epidemiology (ESCAIDE 2019). In addition, the study population were directly invited to participate in the survey by email via field epidemiology networks including TEPHIConnect and national FETP networks. We encouraged survey respondents to forward the survey to their personal and professional network.

\section{Consent}

Participation in this study was voluntary; participants were directed to plain language information sheets, available online in French and English, prior to being able to access the survey. Each participant provided online consent prior to obtaining access to the survey questions. Respondents had the option to navigate the survey and remove or change answers prior to submission.

\section{Ethics}

This survey was approved by the Australian National University Human Research Ethics Committee, ID 2019-068.

\section{Data collection}

We used findings from key informant interviews conducted in 2019 [13, 17] and literature reviews to develop survey questions [18]. The questionnaire was reviewed by key informants and pre-tested with 11 individuals representative of the target population to test for construct and content validity.

The survey was divided into three modules: demographics, epidemiology training, and deployment experience. This paper reports findings from the first two modules. The demographics module included age, gender identity, citizenship, formal education, technical background, years of epidemiology experience, and emergency response experience. For FETP trainees and graduates, we asked about their highest FETP level achieved, based on the globally recognised categories of frontline ( $\leq 6$ months), intermediate ( 9 months -1 year), and advanced ( 2 years) tiers [9].

The survey module on epidemiology training included five broad areas, each with a checkbox list of specific training items: surveillance (6 items), data analysis and assessment (15 items), leadership (9 items), social and communication skills (11 items), and emergency response (14 items). We termed what is commonly known as 'soft skills' or 'interpersonal skills' [19] as 'social and communication skills. The variation in terminology for this set of skills varied across the literature with little consensus, either too narrow in definition for this study or unclearly defined.

This module captured qualitative data via open-ended questions with free-text fields where respondents could identify further training gaps for each area, provide further comments, or list additional training received. Respondent were also asked to comment on whether the knowledge and skills gained during their training, and were appropriate and adequate for emergency response.

We developed and tested the survey in English, which was then translated into French. A native Frenchspeaker re-checked the translation to ensure accuracy 
of meaning. The survey was self-administered online by respondents via REDCap (Research Electronic Data Capture) [20] between October 2019 and February 2020. No incentives were provided for participation.

\section{Data analysis}

Survey data were analysed descriptively in Microsoft Excel (2016) and Stata15 (TX:StataCorp) [21]. Data were analysed to explore associations within and between respondents. We compared self-recounted epidemiology training between FETP and non-FETP and gender. Reported FETP levels were not sub-analysed due to low numbers of respondents from frontline and intermediate programs. We used Pearson Chi-squared $\left(\mathrm{Chi}^{2}\right)$ to test for significant differences between categorical variables. Answers to open-ended questions were analysed using Nvivo11 [22], data familiarisation led to open-coding of text; common categories were created iteratively and merged or expanded as needed [23, 24].

We used the six World Health Organization (WHO) regions to categorise respondents from different geographical areas according to: the Regional Office for Africa (AFRO), Regional Office for the Eastern Mediterranean (EMRO), the Regional Office for Europe (EURO), Pan American Health Organization (PAHO), South-East Asia Regional Office (SEARO), and the Western Pacific Region Office (WPRO) [25].

\section{Results}

Three hundred and thirty individuals consented to participate, of whom $282(85 \%)$ completed the survey; 268 (95\%) in English and 14 (5\%) in French.

Respondents were able to select multiple options regarding how they were informed of the survey, 104 (32\%) indicated Facebook, Twitter, and/or LinkedIn, similarly 105 (32\%) indicated the TEPHINET/TEPHIConnect alumni network, 71 (22\%) indicated they were notified through their country specific FETP network and $42(13 \%)$ through personal or professional contact snowballing sampling.

\section{Demographics}

Gender distribution of respondents was similar, 51\% female $(n=144 / 282)$. The median age of respondents was 39 (range: $23-77$ years) (Table 1). Gender, age distribution, and education level were similar between FETP and non-FETP respondents.

The majority of respondents reported a professional or technical background in epidemiology $(79.8 \%$ $n=225 / 282$, Table 1) with postgraduate or doctoratelevel qualifications $(91.5 \% n=258 / 282$, Table 2). When disaggregated by gender, there were twice as many male laboratory specialists $(65.7 \% n=23 / 35 p=0.028)$
Table 1 Demographic characteristics of epidemiology emergency response survey respondents, 2019-2020 ( $n=282)$

\begin{tabular}{llc}
\hline Category & Variable & Number (\%) \\
\hline Gender & Female & \\
& Male & $144(51.1 \%)$ \\
& Non-conforming & $135(47.9 \%)$ \\
& Prefer not to answer & $0(0 \%)$ \\
& & $3(1.1 \%)$ \\
Age (years) & $<20$ & \\
& $20-29$ & $0(0 \%)$ \\
& $30-39$ & $18(6.4 \%)$ \\
& $40-49$ & $140(49.6 \%)$ \\
& $50-59$ & $78(27.7 \%)$ \\
& $60-69$ & $37(13.1 \%)$ \\
& $70+$ & $7(2.5 \%)$ \\
Technical background & & $2(0.7 \%)$ \\
& & \\
& Epidemiology & $225(79.8 \%)$ \\
& Public Health & $158(56 \%)$ \\
& Medicine & $70(24.8 \%)$ \\
& Laboratory & $35(12.4 \%)$ \\
& Nursing & $25(8.9 \%)$ \\
& Data science & $21(7.4 \%)$ \\
& Veterinary & $19(6.7 \%)$ \\
& Social Science & $14(5.0 \%)$ \\
& Other & $23(8.2 \%)$ \\
\hline
\end{tabular}

${ }^{\text {a }}$ Multiple technical backgrounds per respondent

and significantly more female social scientists $(78.5 \%$ $n=11 / 14 p=0.038)$. There were more females who identified as epidemiologists $(53 \% n=120 / 225)$, nurses $(64 \%$ $n=16 / 25)$, and public health specialists $(53 \% n=84 / 158)$, however, a statistically significant difference was not detected.

Respondents came from 64 countries, with the highest proportion from the United States of America (16.7\% $n=47 / 282)$, Australia $(13.8 \% n=39 / 282)$, and Nigeria $(7.1 \% n=20 / 282)$. When stratified by WHO regions, the highest response was from the America's (PAHO) (Fig. 2). Respondents in AFRO and SEARO were more likely to be male ( $76 \% n=51 / 67,85 \% n=23 / 27$, respectively), with a higher proportion of female respondents in PAHO and WPRO (69\% $n=53 / 76,71 \% n=41 / 57$, respectively). Gender distribution within EMRO and EURO respondents was similar. Age distribution across all regions was similar and FETP respondents made up between $65 \%$ and $89 \%$ of respondents (Fig. 2).

Respondents reported a variety of formal public health and epidemiology training, including, FETP, postgraduate master's programs, doctorate programs, physician public health training, and short courses in specified 
Table 2 Professional background characteristics of epidemiology emergency response survey respondents, 2019-2020 ( $n=282)$

\begin{tabular}{|c|c|c|}
\hline Category & Variable & Number (\%) \\
\hline \multirow[t]{6}{*}{ Epidemiology and Public heath training ${ }^{a}$} & & $n=282$ \\
\hline & Master of Public Health (or similar) & $92(32.6 \%)$ \\
\hline & Other relevant Masters & $13(4.6 \%)$ \\
\hline & Public Health Physician training & $10(3.5 \%)$ \\
\hline & $\mathrm{PhD}$ & $18(6.4 \%)$ \\
\hline & Field Epidemiology Training Program (FETP) & $210(74.5 \%)$ \\
\hline \multirow[t]{4}{*}{ FETP } & & $n=282$ \\
\hline & Yes & $178(63.1 \%)$ \\
\hline & Trainee at time & $32(11.3 \%)$ \\
\hline & No & $72(25.5 \%)$ \\
\hline \multirow[t]{5}{*}{ FETP level } & & $\begin{array}{l}n=210 \\
\quad \text { (including } \\
\text { trainees) }\end{array}$ \\
\hline & Advanced ( 2 years) & $189(90 \%)$ \\
\hline & Intermediate (9 months - 1 year) & $7(3.4 \%)$ \\
\hline & Frontline (<6 months) & $7(3.4 \%)$ \\
\hline & Unanswered & $7(3.4 \%)$ \\
\hline \multirow[t]{4}{*}{ Years since FETP graduation } & & $n=210$ \\
\hline & 10 or less & $157(74.8 \%)$ \\
\hline & $10+$ & $37(17.6 \%)$ \\
\hline & Unanswered & $16(7.6 \%)$ \\
\hline \multirow[t]{9}{*}{ Epidemiology experience } & & $n=282$ \\
\hline & $<1$ years & $12(4.3 \%)$ \\
\hline & $1-<2$ years & $23(8.2 \%)$ \\
\hline & $2-<5$ years & $77(27.3 \%)$ \\
\hline & $5-<8$ years & $64(22.7 \%)$ \\
\hline & $8-<12$ years & $42(14.9 \%)$ \\
\hline & $12+$ years & 59 (20.9\%) \\
\hline & Not applicable & $4(1.4 \%)$ \\
\hline & Unanswered & $1(0.4 \%)$ \\
\hline
\end{tabular}

${ }^{\text {a }}$ Multiple training types per respondent

public health and epidemiology topics (Table 2). The majority of respondents $(74 \%, n=210 / 282)$ indicated they were graduates or trainees of an FETP, $90 \%$ $(n=189 / 210)$ of whom reported to have studied the advanced program (Table 2). Respondents had predominately $(74.8 \%, n=157 / 210)$ graduated from their FETP within the past 10 years (Table 2), with the earliest graduation being 1992. Professional epidemiology experience varied with $40 \%(n=112 / 282)$ of respondents reporting less than 5 years, and $20 \%(n=59 / 282)$ reporting more than 12 years of experience (Table 2 ).

\section{Epidemiology training}

\section{Outbreak and surveillance}

Six outbreak and surveillance categories were listed in the survey (Table 3a). Training in general outbreak and surveillance was commonly reported by the respondents, however less commonly reported was targeted training in emergency response surveillance, community-based surveillance or syndromic surveillance (Table 3a). When comparing the respondents who had completed an FETP with those who had not participated in an FETP, FETP graduates reported higher levels of formal training in all surveillance and outbreak investigation categories (Table 3a).

Respondents highlighted the need for additional opportunities for knowledge consolidation and skill development in both outbreak and surveillance, specifying the need for teaching grounded within the political and social context (Box 1). Additional training was requested on responding to less common events such as environmental, chemical and radiological disasters (Box 1). 


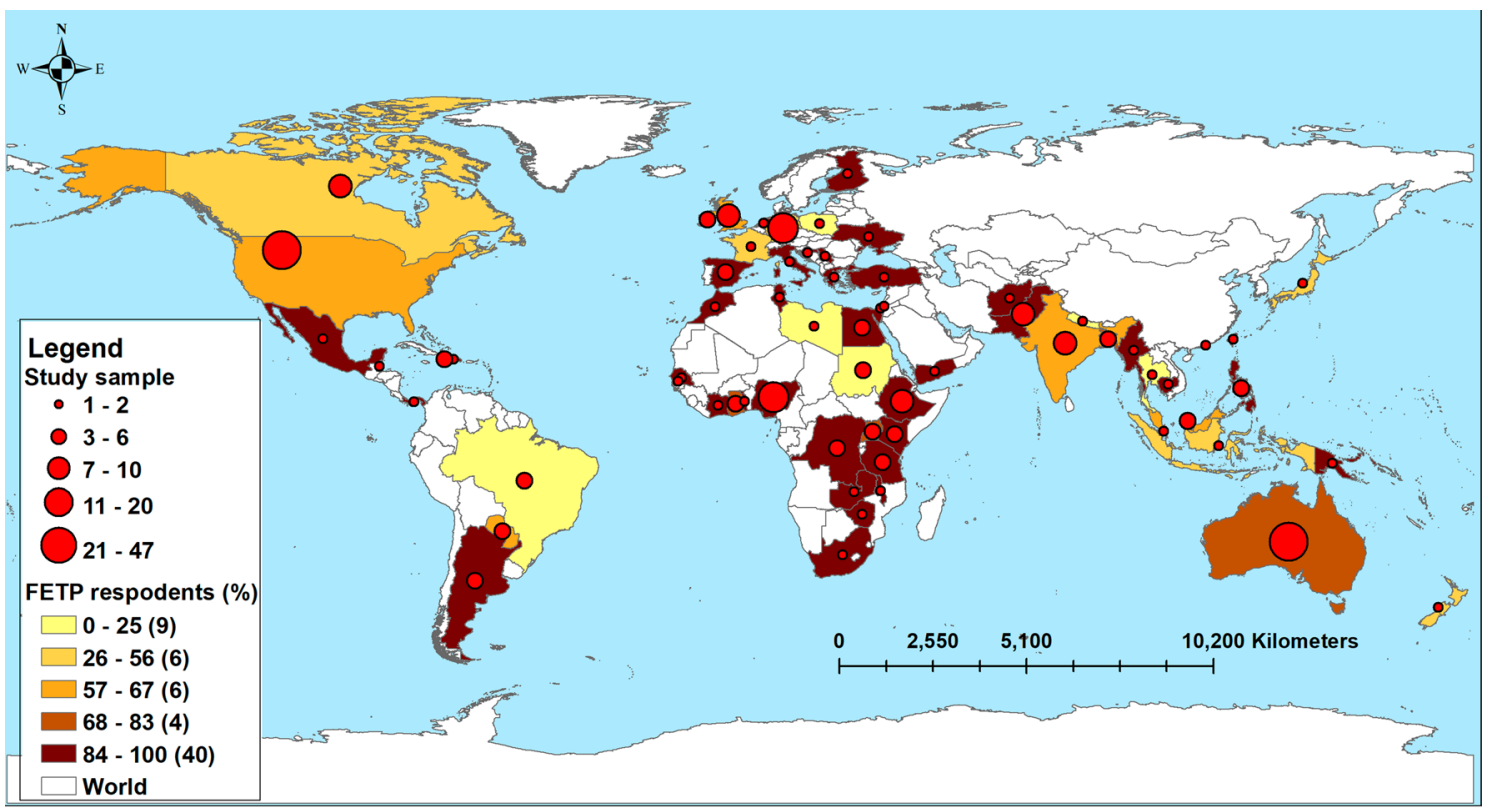

Fig. 2 Distribution of epidemiology emergency response survey respondents by country and training type, 2019-2020 $(n=282)$

\section{Box 1. Outbreak and surveillance training gaps reported by epidemiology emergency response survey respondents, 2019-2020}

$\begin{gathered}\text { Application of } \\ \text { practical skills }\end{gathered}$
apply it in practice."
"I believe that I wanted to have more opportunities to
apply in practice what I learned theoretically."
"While we acquire lots of knowledge, the practical
competencies could be more developed by being in
the field during the training program"
[training] "was mostly based around field epidemiology
in stable, developing world settings. It's mostly related
to the work of government departments."
"The knowledge and skills learnt were more geared
toward outbreak response... Even then, looking back
they were somewhat outdated and didn't necessarily
reflect the political culture within which outbreaks
occur."
[I wanted training] "related to chemical, radiological
and explosive emergencies"

\section{Data analysis and epidemiology methods}

Fifteen emergency response training categories were listed in the survey (Table $3 \mathrm{~b}$ ). Reported training in specific methodology and data analysis skills needed during emergency response was limited. Training on estimation of population size during emergencies was reported by $29.4 \%(n=83 / 282)$, which was similar for both FETP $(29.2 \% n=52 / 178)$ and non-FETP
(27.8\% $n=20 / 72)$ respondents. Thirty-six percent $(n=101 / 282)$ of respondents reported receiving training on how to conduct a needs assessment, and $53.9 \%$ ( $n=152 / 282$ ) on how to conduct a risk assessment. Training in survey development and implementation of specialised survey methods, such as nutrition and mortality surveys, were uncommonly reported $(18.4 \%$ $n=52 / 282$, and $29.8 \% n=84 / 282$, respectively), as were analytical techniques such as transmission trees $(12.8 \%$ $n=36 / 282)$ and spatial analysis $(25.2 \% n=71 / 282)$ (Table $3 b)$. Only $28 \%(n=78 / 282)$ of respondents had received training in managing complex datasets.

The most common statistical and data management packages that respondents reported learning during their training was Epi Info ${ }^{\mathrm{TM}}(72.7 \% n=205 / 282)$, followed by Microsoft Excel $(66.3 \% n=187 / 282)$ and Stata Statistical Software $(43.6 \% n=123 / 282)$ (Table 3b). A higher proportion of FETP graduates were trained in statistical packages compared to non-FETP graduates, with $83.7 \%(n=149 / 178)$ of FETP trained respondents taught Epi Info ${ }^{\mathrm{TM}}$ compared to $43.1 \%(n=31 / 72)$ nonFETP. Microsoft Excel training was reported by $73.6 \%$ $(n=131 / 178)$ of FETP trained respondents compared to $48.6 \%$ ( $n=35 / 752)$ of non-FETP respondents.

Respondents highlighted additional training needs in specific software increasingly used in applied field epidemiology; specifically, training in R statistical software, population denominator estimation, spatial analysis, and geo-spatial mapping. 
Table 3 Reported epidemiology training, comparison between FETP and non-FETP epidemiology emergency response survey respondents, 2019-2020 ( $n=282)$

\begin{tabular}{|c|c|c|c|c|c|c|c|c|}
\hline Section & Category & Topic & Total $n=282$ & Total \% & $\begin{array}{l}\text { Non- } \\
\text { FETP } \\
n=72\end{array}$ & Non-FETP\% & FETP $n=178$ & FETP\% \\
\hline \multirow[t]{7}{*}{ a } & \multicolumn{8}{|c|}{ Training in outbreak and surveillance } \\
\hline & & Basic principles of surveillance & 262 & 92.9 & 58 & 80.6 & 173 & 97.2 \\
\hline & & Syndromic surveillance & 165 & 58.5 & 23 & 31.9 & 118 & 66.3 \\
\hline & & Community-based surveillance & 157 & 55.7 & 34 & 47.2 & 104 & 58.4 \\
\hline & & Emergency response surveillance & 168 & 59.6 & 29 & 40.3 & 119 & 66.8 \\
\hline & & Outbreak investigation steps & 250 & 88.7 & 51 & 70.8 & 168 & 94.4 \\
\hline & & Outbreak investigation methods & 238 & 84.4 & 47 & 65.3 & 160 & 89.9 \\
\hline \multirow[t]{16}{*}{ b } & \multicolumn{8}{|c|}{ Training in analysis and epidemiology methods } \\
\hline & & Rapid survey & 162 & 57.4 & 35 & 48.6 & 107 & 60.1 \\
\hline & & Mortality survey & 84 & 29.8 & 21 & 29.2 & 51 & 28.6 \\
\hline & & Nutrition survey & 52 & 18.4 & 13 & 18.1 & 32 & 18 \\
\hline & & Other survey & 107 & 37.9 & 17 & 23.6 & 75 & 42.1 \\
\hline & & Denominator estimation & 83 & 29.4 & 20 & 27.8 & 52 & 29.2 \\
\hline & & Needs assessment & 101 & 35.8 & 24 & 33.3 & 66 & 34.1 \\
\hline & & Risk assessment & 152 & 53.9 & 34 & 47.2 & 98 & 55.1 \\
\hline & & Managing complex datasets & 78 & 27.7 & 23 & 31.9 & 47 & 26.4 \\
\hline & & $\mathrm{R}$ & 34 & 12.1 & 12 & 16.7 & 18 & 10.1 \\
\hline & & Stata & 123 & 43.6 & 28 & 38.9 & 79 & 44.4 \\
\hline & & Epi Info & 205 & 72.7 & 31 & 43.1 & 149 & 83.7 \\
\hline & & Excel & 187 & 66.3 & 35 & 48.6 & 131 & 73.6 \\
\hline & & Data visualisation & 112 & 39.7 & 26 & 36.1 & 67 & 37.6 \\
\hline & & Transmission trees & 36 & 12.8 & 11 & 15.3 & 20 & 11.2 \\
\hline & & Spatial analysis & 71 & 25.2 & 19 & 26.4 & 38 & 21.4 \\
\hline \multirow[t]{11}{*}{ c } & \multicolumn{8}{|c|}{ Training in leadership and management } \\
\hline & & Evidence-based decision-making & 159 & 56.4 & 35 & 48.6 & 108 & 60.7 \\
\hline & & Mentoring & 98 & 34.8 & 10 & 13.9 & 74 & 41.6 \\
\hline & & Leadership & 130 & 46.1 & 19 & 26.4 & 91 & 51.1 \\
\hline & & Managing a team & 119 & 42.2 & 20 & 27.8 & 85 & 47.8 \\
\hline & & Peer teaching & 93 & 33 & 9 & 12.5 & 70 & 39.3 \\
\hline & & Team work & 184 & 65.2 & 33 & 45.8 & 126 & 70.8 \\
\hline & & Prioritisation & 87 & 30.9 & 17 & 23.6 & 60 & 33.7 \\
\hline & & Delegating responsibility & 73 & 25.9 & 13 & 18.1 & 52 & 29.2 \\
\hline & & Partner coordination & 84 & 29.8 & 15 & 20.8 & 60 & 33.7 \\
\hline & & Reflective practices & 33 & 11.7 & 8 & 11.1 & 21 & 11.8 \\
\hline \multirow[t]{11}{*}{$d$} & \multicolumn{8}{|c|}{ Training in social and communication skills } \\
\hline & & Basic scientific communication skills & 244 & 86.5 & 48 & 66.7 & 166 & 93.3 \\
\hline & & Practical field communication skills & 149 & 52.8 & 24 & 33.3 & 107 & 60.1 \\
\hline & & Media communication & 136 & 48.2 & 24 & 33.3 & 94 & 52.8 \\
\hline & & Cultural competency & 72 & 25.5 & 22 & 30.6 & 42 & 23.6 \\
\hline & & Participant consent & 152 & 53.9 & 30 & 41.7 & 100 & 56.2 \\
\hline & & Stress management & 60 & 21.3 & 9 & 12.5 & 43 & 24.2 \\
\hline & & Social media & 32 & 11.3 & 5 & 6.9 & 22 & 12.4 \\
\hline & & Interview techniques & 144 & 51.1 & 31 & 43.1 & 95 & 53.4 \\
\hline & & Ethics & 169 & 59.9 & 40 & 55.6 & 111 & 62.4 \\
\hline & & Relationship building & 62 & 22 & 14 & 19.4 & 38 & 21.3 \\
\hline
\end{tabular}


Table 3 (continued)

\begin{tabular}{|c|c|c|c|c|c|c|c|c|}
\hline Section & Category & Topic & Total $n=282$ & Total \% & $\begin{array}{l}\text { Non- } \\
\text { FETP } \\
n=72\end{array}$ & Non-FETP\% & FETP $n=178$ & FETP\% \\
\hline \multirow[t]{14}{*}{ e } & \multicolumn{8}{|c|}{ Training in emergency response training } \\
\hline & & $\begin{array}{l}\text { Role of the epidemiologist during emergency } \\
\text { response }\end{array}$ & 169 & 59.9 & 33 & 45.8 & 113 & 63.5 \\
\hline & & Epidemiology of public health disasters & 166 & 58.9 & 32 & 44.4 & 114 & 64 \\
\hline & & Humanitarian principles & 67 & 23.8 & 18 & 25 & 42 & 23.6 \\
\hline & & Principles of escalation/scaling a response & 45 & 16 & 9 & 12.5 & 30 & 16.9 \\
\hline & & Methods of data collection in an emergency & 147 & 52.1 & 31 & 43.1 & 96 & 53.9 \\
\hline & & Ethics during emergencies & 82 & 29.1 & 18 & 25 & 53 & 29.8 \\
\hline & & IMS_Incident Management System & 73 & 25.9 & 14 & 19.4 & 46 & 25.8 \\
\hline & & EOC role-Emergency Operations Centre & 93 & 33 & 17 & 23.6 & 63 & 35.4 \\
\hline & & IHR_International Health Regulations & 121 & 42.9 & 15 & 20.8 & 87 & 48.9 \\
\hline & & $\begin{array}{l}\text { HeRAMS: Health Resources Availability Monitoring } \\
\text { System }\end{array}$ & 11 & 3.9 & 1 & 1.4 & 8 & 4.5 \\
\hline & & $\begin{array}{l}\text { EWARS: Early Warning, Alert and Response System } \\
\text { (EWARS in a box) }\end{array}$ & 79 & 28 & 12 & 16.7 & 58 & 32.6 \\
\hline & & $\begin{array}{l}\text { Personal safety (use of PPE- personal protective } \\
\text { equipment) }\end{array}$ & 130 & 46.1 & 26 & 36.1 & 88 & 49.4 \\
\hline & & Border control (POE_-point of entry) & 46 & 16.3 & 8 & 11.1 & 30 & 16.9 \\
\hline
\end{tabular}

\section{Leadership and management}

Ten leadership and management training categories were listed in the survey (Table 3c) Sixty-five percent $(n=184 / 282)$ of respondents reported having received training in teamwork, and $56.4 \%$ ( $n=159 / 282)$ reported training in evidencebased decision-making. Responses to the remaining eight items in the leadership and management module of the survey indicated that these were missing from most training programs. Less than $50 \%$ of respondents reported having learnt leadership and management skills during their applied epidemiology training (Table 3c). For example, only $11.7 \%$ $(n=33 / 282)$ of respondents reported training in skill development related to reflective practices.

Although leadership training was not widely reported, FETP trained respondents reported a higher percentage of training in all leadership categories compared to non-FETP, especially in mentoring and peer teaching (Table 3c). Within each category in this section, males reported much higher leadership and management exposure, with the exception of peer teaching. Of note, during training $45.9 \%(n=62 / 135)$ of male respondents reported having been taught mentoring, compared to $24.3 \%(n=35 / 144)$ of female respondents, $61.5 \%(n=83 / 135)$ of males reported training in leadership skills compared to $31.3 \%(n=45 / 144)$ of females, and $34.1 \%$ $(n=46 / 135)$ of males reported training in delegation skills compared to $17.4 \%(n=25 / 144)$ of females (Table 4$)$.
Table 4 Reported training in leadership and management, comparison of epidemiology emergency response survey by gender, 2019-2020 ( $n=282)$

\begin{tabular}{lll}
\hline Topic & Female $\boldsymbol{n}=\mathbf{1 4 4}(\mathbf{\%})$ & Male $\boldsymbol{n}=\mathbf{1 3 5}(\mathbf{\%})$ \\
\hline $\begin{array}{l}\text { Evidence-based decision- } \\
\text { making }\end{array}$ & $77(53.5 \%)$ & $80(59.3 \%)$ \\
Mentoring & $35(24.3 \%)$ & $62(45.9 \%)$ \\
Leadership & $45(31.3 \%)$ & $83(61.5 \%)$ \\
Managing a team & $45(31.3 \%)$ & $72(53.3 \%)$ \\
Peer teaching & $51(35.4 \%)$ & $42(31.1 \%)$ \\
Team work & $89(61.8 \%)$ & $92(68.1 \%)$ \\
Prioritisation & $38(26.4 \%)$ & $47(34.8 \%)$ \\
Delegating responsibility & $25(17.4 \%)$ & $46(34.1 \%)$ \\
Partner coordination & $37(25.7 \%)$ & $45(33.3 \%)$ \\
\hline
\end{tabular}

\section{Social and communication skills}

Ten training categories were listed in the survey under social and communication skills (Table $3 \mathrm{~d}$ ). The majority $(86.5 \% n=244 / 282)$ of respondents reported training in basic scientific communication such as report writing and presentation preparation. Training in other communication techniques was less frequently reported; including training in practical communication in the field $(52.8 \% n=149 / 282)$, media communication $(48.2 \%$ 
$n=136 / 282)$, cultural competence $(25.5 \% n=72 / 282)$, and social media communication $(11.3 \% n=32 / 282)$ (Table 3d). Approximately 20\% of respondents reported training in stress management $(n=60 / 282)$ and relationship building $(n=62 / 282)$. Interview techniques, issues related to consent, and practical ethical approaches to field work were reported by just over half of the respondents (Table 3d). With the exception of cultural competence, non-FETP trained participants reported less training than FETPs to each category in this section (Table $3 \mathrm{~d}$ ).

Free text responses highlighted the need for more training in social and communication skills, (Box 2). Additionally, respondents indicated the need for further training in traditional media and social media. (Box 2). Respondents also stated that training with a focus on cultural, political, and contextual understanding was needed, as was training on qualitative research methods, stress management, and prioritisation (Box 2).

\section{Box 2. Social and communication training gaps reported by epidemiology emergency response survey respondents, 2019-2020}

Communication "I think a really valuable skill that should be taught in
epidemiology is how to influence others with the
data story. This isn't about most fancy, complicated
analysis, but about working out what's important in
the data for decision-making"

\section{Emergency response}

Fourteen emergency response training items were listed in the survey with half $(n=7)$ of them reported by less than $30 \%$ of respondents each (Table 3e). Non-FETP respondents reported less training than FETP graduates in each of these emergency response categories (Table 3e).

When respondents were asked whether they believed emergency response training should be a core component of applied epidemiology training, almost $75 \%$ ( $n=211 / 282)$ replied yes, and $18 \%(n=50 / 282)$ suggested it should be optional.

Despite relatively low proportions of respondents having received formal training in the listed emergency response categories, 64\% $(n=181 / 282)$ agreed or strongly agreed that their epidemiology training gave them the required knowledge to work as an epidemiologist during emergency response (Fig. 3). Additionally, 65\% $(n=172 / 282)$ believed they had learnt the required skills for epidemiology emergency response (Fig. 4). FETP respondents were more likely to answer positively to these questions than non-FETP (Figs. 3 and 4).

Respondents requested additional training on the role of an epidemiologist during emergency response, personal and professional characteristics needed during a response, epidemiology methods in emergency response, humanitarian principles, as well as training on the emergency response structure (Box 3).

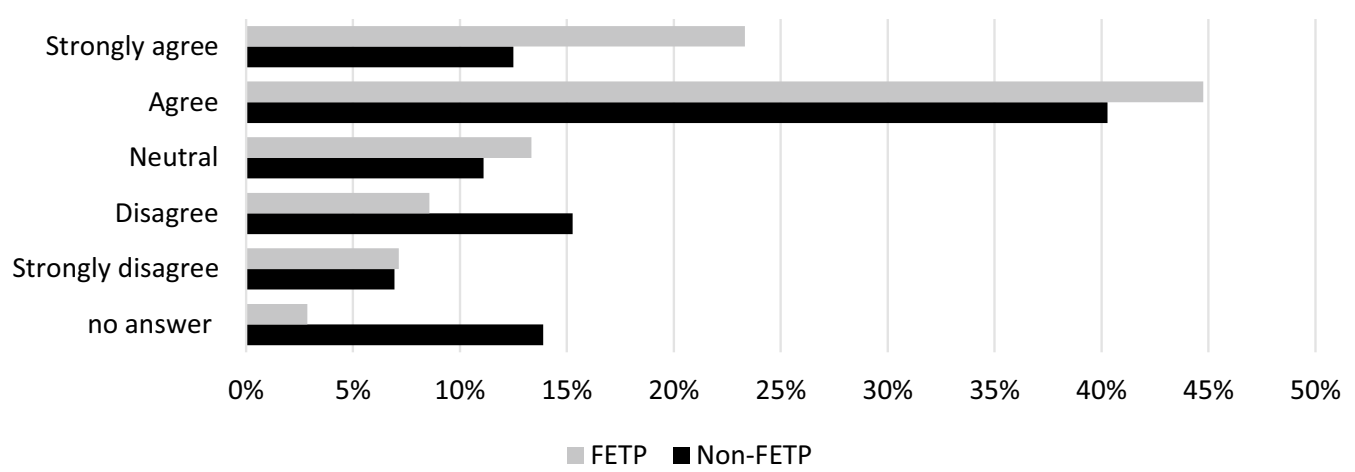

Fig. 3 FETP and non-FETP respondents' perceptions of epidemiology training providing the knowledge required for emergency responses $(n=282)$ 


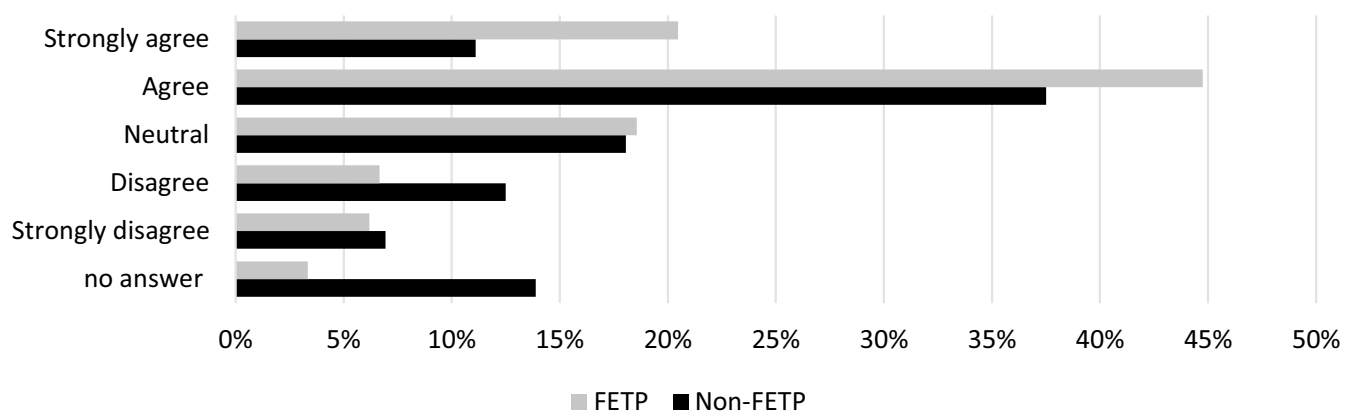

Fig. 4 FETP and non-FETP respondents' perceptions of epidemiology training providing the skill required for emergency responses $(n=282)$

\section{Box 3 Emergency response training gaps reported by epidemiology emergency response survey respondents, 2019-2020}

Emergency
response
pleted the program should be in the field"
"Specific things like bioterrorism and natural disasters
and hurricane response"
"Critical skills to data analysis and collection during
an emergency, rarely having a denominator, work-
ing with dirty data, working with MoH's [Ministry of
Health] without statistical packages"
"Did not learn enough about the different approaches
and methods that are/should be used in an emer-
gency setting vs a regular ongoing surveillance or
outbreak response setting"
"Thinking systems in the middle of an emergency"
"A session on the realities of an emergency situation
would be useful"
"There was minimal relevant to emergency response
or low resource settings"
"How humanitarian responses are structured-what
is happening around you in such a response and
concrete feedback about where epi skills and infor-
mation can serve those components
"There were no emergency response topics covered in
my epi training... no mention of IHR [International
Health Regulations]" "
Role of Field Epidemiologist during Humanitarian
crisis still confuses me"
"Even at the advanced level and despite being "on the
ground", does not have the capacity of those trained
in the roles of the epidemiologist in emergency situ-
ations or health crises, in rapid interventions"
"In a situation with an environmental disaster (e.g.
air pollution), the epidemiologist has no prepara-
tion on his role in such an event. Other areas: Mass
casualty, major water contamination, exposure to
chemicals due to explosions, etc... responders are
prepared, but the epidemiologist is not"

\section{Discussion}

Our survey on epidemiology training for emergency response identified core training needs of the applied epidemiology workforce. Our findings indicate that respondents believe their training in outbreak and surveillance, regardless of different training models, was sufficient. Respondents did, however, identify training gaps in the areas of social and communication skills, leadership and management, data analysis, epidemiology methods, and emergency response. Additionally, respondents identified that training methods needed to focus more on application of practical skills.

The COVID-19 pandemic has been another reminder of the importance of communication skills in connecting with the public during a public health emergency and the essential role of effective communication in the successful implementation of control measures [26-28]. Applied epidemiologists are often required to draw on a variety and diverse range of communication skills in order to effect change. These skills range from communicating risk to the public, communicating methods and findings to peers and designing messages that will support policy and decision-makers to implement an effective public health response. As the applied epidemiology definition by Thacker and Buffington [6] states, applied epidemiology is about "transforming findings to policy and action", and as one of the respondents wrote, "it is not just about collecting data but it is about influencing others with the story". Our survey identified gaps in applied epidemiology training in the areas of cultural competence, understanding the socio-political context, and anthropological principles. This training deficit was documented in a study of emergency response epidemiologists who responded to the 2014-2016 West Africa Ebola crisis [19], and a study looking to understand outbreak investigation training 
[29]. Despite the crucial need for these skills to function optimally as applied epidemiologists, survey respondents highlighted that these skills were not routinely taught in their applied epidemiology training.

Leadership and management skills are crucial for responding effectively and efficiently to public health events. One of the primary aims of FETPs is to train future public health leaders $[8,30,31]$, with leadership and management listed as a core FETP competency. However, all training categories in the leadership and management section of our survey were uncommonly reported by respondents, with the exception of working in a team. Holding et al. [19] study post the West Africa Ebola crisis found a similar deficit in leadership training, as did Samet and Brownson [32] in their study of epidemiology graduates in the United States. A key characteristic of applied epidemiology is making evidence-based decisions, however only about half of respondents reported having received training on this.

While we did not identify any significant difference between respondents in regards to gender, level of education, or type of education, we identified significant difference in leadership and decision-making training between males and females. In this self-reported survey, this raises questions on whether leadership has the same meaning or interpretation across genders. The difference in response between genders may be linked to stereotypes and individual definitions around what constitutes leadership [33-35]. Traditionally, leadership has been linked to masculine traits, which then also devalue the feminine style of leadership [34, 35]. Johnson and Blair discuss how COVID-19 is shifting this understanding of leadership [34]. This concept of gender is important for leadership in emergencies and associated training needs further exploration through operational research.

When focusing on technical epidemiological skills, few respondents reported training in estimation of population density or specialised surveys such as mortality or nutrition surveys. Médecins Sans Frontières (MSF) have listed key competencies for epidemiologists in emergency response; including experience in practical applied research methods, as well as survey development and implementation (including mortality and nutritional surveys) [36]. Few respondents reported having received training in these specialised skills. Graduates of FETP programs who are trained to respond to public health events, without training in population estimation, population surveys, risk and needs assessment, would struggle to respond effectively to public health emergencies. Standardisation of FETP curriculum and core concepts regarding emergency response is urgently needed [37].

In addition, respondents to our survey highlighted the need to further understand the role of an epidemiologist during an emergency response, and the emergency response structure. Emergency response, whether it be a local or international public health emergency, should be a core competency of applied epidemiologists, who are often early responders. To be adequately equipped, this workforce needs more specialised skills in emergency response which appear to be neglected in the current models of applied epidemiology training. Continuous professional development activities should be considered for this workforce to ensure skills and knowledge is maintained, developed and responsive to changes in the field epidemiology emergency response landscape.

In our survey, there was an evident lack of training in practices that support the applied epidemiology workforce to remain strong and healthy and prevent burnout, such as stress management and reflective practices. Many countries struggle to retain field epidemiologists due to occupational burnout or career path limitations [7, 31, 38]. Ryu et al. [7] study on field epidemiology occupational stress, suggests that burnout is a very real concern given the frontline nature of outbreak and emergency response.

Although this survey focused on individuals' training experience, our findings may be used to explore challenges to the broader workforce. We need to consider what capacities are required for the management and control of public health emergencies, not just the individual needs of each trainee [39]. Investment in a resilient applied epidemiology workforce means ensuring the workforce have the skills and knowledge needed to fulfil the various health security roles they will play now and in the future [5, 29, 32, 37].

\section{Study limitations}

It is important to recognise some limitations with this study that may impact on our findings. We collected data through an opt-in self-administered online survey. The survey was not offered in any other format, therefore those without internet access were not able to participate, which means we may have excluded people working at the community level. We attempted to limit the effect of selection-biases introduced because of our approach to sampling by using multiple sources and methods to recruit participants. We offered the survey in two languages, French and English, as these are the common languages used during recent international emergency responses. We are cautious in generalising our findings to the applied epidemiology workforce, however, our sample size was large enough to identify common categories.

It was difficult for us to identify an accurate study target population sampling frame. The applied epidemiology workforce in most countries is informal and 
often poorly documented with the definition of 'epidemiologist' varying between individuals and organisations. The work title of an epidemiologist is largely through self-identification. Due to this limitation, we designed a cross-sectional survey distributed through professional networks. The study target population was defined as anyone who self-identified as having worked in an applied epidemiology role. However, because of this design we are unable to comment on how survey respondents differed from non-respondents.

As the timing of the survey was not during or immediately after the respondents' training in epidemiology, recall bias may have affected the information obtained. Respondents also had varying years and types of experience and time since graduation. This gap between training and our survey may have been advantageous as respondents may have had time to reflect on what went well and what could be improved [40, 41].

In recent years, FETP training has expanded to three levels including a frontline and intermediate program, although few representatives from these programs accessed the survey. Future applied epidemiology workforce surveys should be targeted at graduates of these programs. Despite these limitations, our study offers insight into gaps in training for applied epidemiologists, which is supported by other operational research.

\section{Conclusion}

Our survey identified that applied epidemiology training needs to evolve to provide capacity and skills to respond to dynamic and complex public health emergencies. There is a need to address the identified training gaps in leadership, communication and social skills, as well as emergency response. This will strengthen the applied epidemiology workforce, as well as the health systems they function within and the local, national, regional and global emergencies they respond to. Continuous professional development activities must also be available to support the current workforce adapt, as well as augment new graduates to be suitably skilled for the challenges ahead.

\footnotetext{
Abbreviations

AFRO: Regional Office for Africa; COVID-19: Coronavirus Disease 2019; EMRO: Regional Office for the Eastern Mediterranean; EOC: Emergency Operations Centre; ESCAIDE: European Scientific Conference on Applied Infectious Disease Epidemiology; EURO: Regional Office for Europe; EWARS: Early Warning, Alert, and Response System; FETP: Field Epidemiology Training Program; HeRAMS: Health Resources Availability Monitoring System; IHR: International Health Regulations; IMS: Incident management systems; MPH: Master of Public Health; MSF: Médecins Sans Frontières; PAHO: The Pan American Health Organization; POE: Point of Entry; PPE: Personal protective equipment; REDCap: Research Electronic Data Capture; SEARO: South-East Asia Regional Office; TEPHINET: Training Programs in Epidemiology and Public Health
}

Interventions Network; TEPHIConnect: TEPHINET alumni network; WHO: World Health Organization; WPRO: Western Pacific Region Office.

\section{Acknowledgements}

Thank you to the survey respondents for sharing your knowledge and experience. Thank you to TEPHIConnect, FETP program directors, and TEPHINET networks, for distributing the survey to members and for support with recruitment. Thank you also to Dr Kinley Wangdi for support with mapping, and Dr Alice Richardson for statistical advice. Finally, thank you for the constructive comments made by our reviewers to strengthen this paper.

\section{Authors' contributions}

AP wrote the manuscript and is leading the study; $T H, B O, D D, M K$ supported study design development, $\mathrm{TH}, \mathrm{BO}, \mathrm{DD}, \mathrm{MK}, \mathrm{SC}$ supported data analysis interpretation and revised the manuscript critically. All authors read and approved the final manuscript.

\section{Funding}

This research received no specific grant from any funding agency in the public, commercial or not-for-profit sectors. AP receives Commonwealth and ANU science merit scholarships, along with funding from the Australian National Health. AP and SC are funded through the Medical Research Council (NHMRC) Integrated Systems for Epidemic Response (APP1 107393). MK is supported by an NHMRC fellowship (APP1145997) and receives funding from the NHMRC for Integrated Systems for Epidemic Response. The funders did not have any role in the study design, data collection and analysis, decision to publish or preparation of the manuscript.

\section{Availability of data and materials}

All data relevant to this manuscript are included within the manuscript tables, figures and/or reference links.

\section{Declarations}

\section{Ethics approval and consent to participate}

This survey was approved by the Australian National University Human Research Ethics Committee, ID 2019-068. Each participant completed a consent form prior to participation.

\section{Consent for publication}

Not applicable.

\section{Competing interests}

The authors declare that they have no competing interests.

\section{Author details}

${ }^{1}$ National Centre for Epidemiology and Population Health, Research School of Population Health, The Australian National University, Building 62 Mills Road, Acton, Australian Capital Territory, Australia. ${ }^{2}$ University of Newcastle, Newcastle, New South Wales, Australia. ${ }^{3}$ World Health Organization, Health Emergency Information and Risk Assessment, Geneva, Switzerland.

Received: 30 November 2020 Accepted: 19 April 2021

Published online: 29 April 2021

\section{References}

1. O'Carroll P, Kirk M, Baggett K, Herrera D. The global field epidemiology roadmap. 2018 (cited 2020 Sep 9). https://www.tephinet.org/sites/tephi net/files/content/attachment/2018-11-26/The\%20Global\%20Field\% 20Epidemiology\%20Roadmap_11.26.18.FINAL_.pdf.

2. World Health Organization. Working for health and growth: investing in the health workforce. World Health Organization; 2016 (cited 2020 Sep 11). Report No.: ISBN 978924151130 8. https://apps.who.int/iris/bitst ream/handle/10665/250047/9789241511308-eng.pdf;jsessionid=935A6 223EF4D1BFCE447E2ABDD915AC3? sequence $=1$.

3. Dhama K, Patel SK, Sharun K, Pathak M, Tiwari R, Yatoo MI, et al. SARSCoV-2 jumping the species barrier: Zoonotic lessons from SARS, MERS 
and recent advances to combat this pandemic virus. Travel Med Infect Dis. 2020;37:101830

4. Nsubuga P, White M, Fontaine R, Simone P. Training programmes for field epidemiology. Lancet. 2008;371(9613):630-1.

5. Bensyl DM, King ME, Greiner A. Applied epidemiology training needs for the modern epidemiologist. Am J Epidemiol. 2019;188(5):830-5.

6. Thacker SB, Buffington J. Applied epidemiology for the 21st Century. Int J Epidemiol. 2001;30(2):320-5.

7. Ryu S, Kim YW, Kim S, Liao Q, Cowling BJ, Lee C-S. Occupational stress among field epidemiologists in field epidemiology training programs from the public health sector. Int J Environ Res Public Health. 2019;16(18):3427

8. Schneider D, Evering-Watley M, Walke H, Bloland PB. Training the global public health workforce through applied epidemiology training programs: CDC's experience, 1951-2011. Public Health Rev. 2011:33(1):190-203.

9. Training Programs |TEPHINET (cited 2020 Sep 30). https://www.tephinet. org/training-programs.

10. Traicoff DA, Walke HT, Jones DS, Gogstad EK, Imtiaz R, White ME. Replicating success: developing a standard FETP curriculum. Public Health Rep. 2008;123(Suppl 1):28-34.

11. Riley M, Health JBS of P. Concentrations. Johns Hopkins Bloomberg School of Public Health (cited 2020 Oct 24). https://www.jhsph.edu/ academics/degree-programs/master-of-public-health/curriculum/conce ntrations.html.

12. London School Hygiene and Tropical Medicine. LSHTM MSc Public Health, programme handbook 2020-21 (cited 2020 Oct 24). https://www. Ishtm.ac.uk/files/ph-handbook.pdf.

13. Parry, Amy Elizabeth, Kirk, MD, Durrheim, DN, Olowokure, B, Colquhoun S, Housen T. Emergency response and the need for collective competence in epidemiological teams. Bull World Health Organ. 2021 (cited 2021 Mar 20); early release. https://cdn.who.int/media/docs/default-source/bulle tin/online-first/blt.20.276998.pdf?sfvrsn=e2e61 bfo 5.

14. Parry AE, Kirk MD, Durrheim DN, Olowokure B, Housen T. Study protocol: building an evidence base for epidemiology emergency response, a mixed-methods study. BMJ Open. 2020;10(6):e037326.

15. Deborah K. Padget. SAGE Publications: Qualitative and Mixed Methods in Public Health; 2012.

16. Teddlie C, Yu F. Mixed methods sampling: a typology with examples. Mix Methods Res. 2007;1(1):77-100

17. Parry AE, Kirk MD, Colquhoun SM, Housen T. Enhancing the effectiveness of the epidemiology workforce responding to Covid-19. BMJ. 2020 (cited 2020 Jul 21);368(m1075). https://www.bmj.com/content/368/bmj. m1075/rr-0.

18. David de Vaus. Surveys in Social Research. 6th edition. Allen \& Unwin Australia; 2014

19. Holding M, Ihekweazu C, Stuart JM, Oliver I. Learning from the epidemiological response to the 2014/15 ebola virus disease outbreak. J Epidemiol Glob Health. 2019;9(3):169-75.

20. About-REDCap (cited 2020 Sep 30). https://projectredcap.org/about/

21. StataCorp. Stata Statistical Software. College Station, TX: StataCorp LLC; 2017.

22. QSR International Pty Ltd. NVivo 11. https://www.qsrinternational.com/ nvivo-qualitative-data-analysis-software/home.

23. Liamputtong P. Qualitative Research Methods. South Melbourne, Vic., Oxford University Press; 2009 (cited 2018 Jul 25). https://trove.nla.gov.au/ work/7394612.

24. Braun V, Clarke V. Using thematic analysis in psychology. Qual Res Psychol. 2006;3(2):77-101.

25. Regional offices (cited 2020 Sep 30). https://www.who.int/about/whowe-are/regional-offices.

26. Rubinelli S, Myers K, Rosenbaum M, Davis D. Implications of the current COVID-19 pandemic for communication in healthcare. Patient Educ Couns. 2020:103(6):1067-9.

27. Cooley L. Trust and communication: responding to uncertainty. J Patient Exp. 2020:7(3):277-8.
28. Finset A, Bosworth $H$, Butow P, Gulbrandsen P, Hulsman RL, Pieterse $\mathrm{AH}$, et al. Effective health communication - a key factor in fighting the COVID-19 pandemic. Patient Educ Couns. 2020;103(5):873-6.

29. Forbes O, Davis S, Dyda A, Rosewell A, Williams S, Moffatt C, et al. Expert perspectives on outbreak investigation training: a quality improvement exercise. Glob Biosecurity. 2020 (cited 2020 Oct 29); 1 (4). http://jglobalbio security.com/articles/53/print/.

30. Training programmes for field epidemiology — the Lancet (cited 2020 Oct 27). https://www.thelancet.com/journals/lancet/article/PIIS01406736086 02810/fulltext?rss=yes.

31. Jones DS, Dicker RC, Fontaine RE, Boore AL, Omolo JO, Ashgar RJ, et al. Building global epidemiology and response capacity with field epidemiology training programs. Emerg Infect Dis. 2017;23(Suppl 1):S158-65.

32. Samet JM, Brownson RC. Epidemiology in a changing world. Am J Prev Med. 2014;47(5):S383-5.

33. Dhatt R, Theobald S, Buzuzi S, Ros B, Vong S, Muraya K, et al. The role of women's leadership and gender equity in leadership and health system strengthening. Glob Health Epidemiol Genomics. 2017 ed (cited 2020 Oct 27);2. https://www.cambridge.org/core/journals/global-health-epide miology-and-genomics/article/role-of-womens-leadership-and-genderequity-in-leadership-and-health-system-strengthening/A6AEB63AFE 17295E0EF9E40741A2EC5B.

34. Johnson C, Williams B. Gender and political leadership in a time of COVID. Polit Gend. 2020. pp. 1-8.

35. Randell S, Yerbury H. An exploration of the metaphors and images used to describe leadership in two different cultural contexts. Front Educ. 2020 (cited 2020 Oct 31):5. https://www.frontiersin.org/articles/10.3389/feduc. 2020.00151/full?utm_source=F-AAE\&utm_medium=EMLF\&utm_campa ign=MRK_1411754_21_Educat_20200825_arts_A.

36. Médecins Sans Frontières (MSF) International. Who we are. Médecins Sans Frontières (MSF) International (cited 2019 Jul 15). https://www.msf. org/who-we-are.

37. Thoroughman D. Applied epidemiology competencies: experience in the field. Public Health Rep. 2008;123(Suppl 1):8-10.

38. Pourshaban D, Basurto-Dávila R, Shih M. Building and sustaining strong public health agencies: determinants of workforce turnover. J Public Health Manag Pract JPHMP. 2015;21(Suppl 6):S80-90.

39. Gebbie KM. The public health workforce: key to public health infrastructure. Am J Public Health. 1999;89(5):660-1.

40. Bernard AW, Gorgas D, Greenberger S, Jacques A, Khandelwal S. The use of reflection in emergency medicine education. Acad Emerg Med. 2012:19(8):978-82.

41. World Health Organization. Guidance for after action review (AAR) Geneva, Switzerland: World Health Organization; 2019 (cited 2019 Oct 8). Report No.: WHO/WHE/CPI/2019.4. https://apps.who.int/iris/bitstream/ handle/10665/311537/WHO-WHE-CPI-2019.4-eng.pdf?sequence=1.

\section{Publisher's Note}

Springer Nature remains neutral with regard to jurisdictional claims in published maps and institutional affiliations.

Ready to submit your research? Choose BMC and benefit from:

- fast, convenient online submission

- thorough peer review by experienced researchers in your field

- rapid publication on acceptance

- support for research data, including large and complex data types

- gold Open Access which fosters wider collaboration and increased citations

- maximum visibility for your research: over 100M website views per year

At BMC, research is always in progress.

Learn more biomedcentral.com/submissions 